(2) Open Access Full Text Article

ORIGINALRESEARCH

\title{
Assessment of Healthy Diet and Physical Activity Among Students of Mekelle University, Northern Ethiopia: A Cross-Sectional Study
}

\section{Gebrezabher Niguse Hailu (iD Haftu Berhe Gebru Desta Siyoum Belay}

School of Nursing, Mekelle University, Mekelle, Ethiopia
Correspondence: Gebrezabher Niguse Hailu

Email gerigereking12@gmail.com
Introduction: The promotion and maintenance of a healthy lifestyle remains a persistent challenge globally. As a result, the deleterious effects of chronic diseases are escalating globally. But, nevertheless healthy diet and physical activity practices are not yet assessed among university students in Ethiopia. Therefore, this study was aimed at assessing healthy diet and physical activity among Mekelle university students from September 2019 to June 2020.

Methods: We used cross-sectional study design and the study was carried out at Mekelle University among undergraduate students. Data collected by using normalized and pre-tested questionnaire. Binary logistic regression model was used to identify factors associated with diet and physical activity. Multivariable analysis was used to determine significant predictors of healthy diet and physical activity.

Results: The practice of healthy diet and physical activity was $68.20 \%$ (poor), $31.75 \%$ (good) and 59.70\% (poor), 40.3\% (good), respectively. This study showed that college (AOR: 0.69, CI: [0.034-0.137], AOR: 0.20, 95\% CI: [0.104-0.391]) and parent's resident (AOR: 1.331, 95\% CI: [0.156-0.698]) were significant predictors of healthy diet practice of study participants, whereas gender (AOR: 3.909, 95\% CI: [2.549-5.993]) and year of education (AOR: 0.411, 95\% CI: [0.204-0.826]), college (AOR: 0.358, 95\% CI: [0.212$0.604]$ ), were significantly associated with physical activity practice.

Conclusion: The study revealed that the majority of the study participants were poor in both healthy diet and physical activity practices.

Keywords: healthy diet, physical activity, university students, Mekelle, Ethiopia

\section{Introduction}

Practicing of healthy diet and regular physical activity is prominent part of healthy life style which have significant mental and physical health benefits. Currently, lifestyle has become an important predictor of health status. For instance, the World Health Organization (WHO) has declared that $60 \%$ of an individual's health-related quality of life depends on his/her lifestyle. ${ }^{1}$

Non-communicable diseases are increasing globally and resulted a deleterious effect. Unhealthy diet and physically inactive have been strongly associated with these diseases. 2,3

WHO global health status (2014) reported that in 2012, alcohol consumption was responsible for about 5.9\% (3.3 million) deaths globally and 5.1\% of disabilityadjusted life years (DALYs). By the same taken, insufficient physical activity has 
contributed to 3.2 million deaths and 69.3 million DALYs each year. It also showed that cardiovascular disease due to unhealthy life style was attributed for $46 \%$ (17.5 million) deaths by 2012. Of these deaths, about 7.4 million were due to heart attacks (ischemic heart disease) and 6.7 million were due to strokes. ${ }^{4}$

Many studies have shown that an unhealthy diet and physical inactivity increase the risk of diabetes, osteoporosis, obesity and cardiovascular diseases. ${ }^{5-10}$

Several international reports have indicated that noncommunicable diseases affect not only adults but also starting to affect the younger generations. ${ }^{11-14}$ For instance, study conducted among Palestinian students at An-Najah National University revealed that the prevalence of overweight and obesity was $26.2 \%$, with a significant increase among males 36.4\%) compared with females $19.1 \%$. The prevalence of metabolic syndrome among obese and overweight was $28.6 \%{ }^{13}$ Another study conducted in Ghana to assess the prevalence of pre-hypertension and hypertension and its related risk factors among undergraduate students in a Tertiary institution showed that twelve $2.2 \%$ of the students were hypertensive, whilst pre-hypertension was prevalent in $26.1 \%$ of the students. ${ }^{12}$

It is obvious that most young adult population is university students. These students subjected to mutable transitional period of new independence life expecting to be self-reliant but, nevertheless are prone to engage in different tasks which are considerable contributors to unhealthy lifestyles. $^{15,16}$

Numerous studies have shown that university students often have poor eating habits. For instance, finding from both Western and Arab countries have indicated that university students are not taking healthy diet and not following the recommended level of physical activity. ${ }^{15,17-20}$

Although there are increasing efforts to make university students practice healthy promoting behaviors particularly following recommended diet and regular physical activity, $^{21,22}$ there have been no reported healthy Campus initiatives. It has been also noted that there is no known study that has assessed the healthy diet and physical activity practice of university students in Ethiopia. Therefore, this study aimed to assess healthy diet and physical activity practices among students of Mekelle University from September 2019 to June 2020. Findings of the current study are expected to direct efforts and actions toward enhancing the health of those in need.

\section{Methods and Materials}

\section{Study Design, Area and Period}

Cross-sectional study design was carried out to assess the practice of healthy diet and physical activity among study participants at Mekelle University, from September 2019 to June 2020. Mekelle University is one of the largest public universities in Ethiopia.

\section{Source and Study of Population}

All under graduate Mekelle university students were taken as source population whereas students unable to attend due to serious health problems or other considerable issues were excluded from the study.

\section{Sample Size Determination}

The sample size was determined by using the formula $[\mathrm{n}=$ $\left.\left[(\mathrm{Za} / 2)^{2} * \mathrm{P}(1-\mathrm{P})\right] / \mathrm{d}^{2}\right]$ by considering $95 \%$ confidence level of $\mathrm{Za} / 2=1.96$, margin of error $5 \%$, proportion $(\mathrm{p})$ of $50 \%$ and the final sample size was 422 . Due to the sampling technique was involved multistage a 1.5 design effect was used. The required sample was 633 .

\section{Sampling Technique and Sampling Procedure}

The best fitted sampling method was multi stage simple random sampling where each selected college was divided in to departments. And then each department was divided in to classes and sample was taken from each class using simple random sampling method.

\section{Data Collection Tool and Technique}

Research assistants collected the data by using normalized self-administered questionnaire. The questionnaire includes two sections. The first section included questions to ask about demographic characteristics. ${ }^{18}$

The second section contained 17 questions (9 questions for healthy diet and 8 questions for physical activity) to assess the healthy diet and physical activity of the students. The tool for measuring the healthy diet and physical activity practices of college students was developed by Walker, Sechrist, and Pender. ${ }^{23}$ Participants indicated the frequency in which they participate in each using a fourpoint scale ranging from 1 (never) to 4 (routinely). Students who scored above the mean score for healthy diet and physical activity questionnaire were considered as a good and those who scored below the mean score were considered as poor. 


\section{Data Quality Control}

The tool used to assess healthy diet and physical activity among students was standardized. ${ }^{23}$ The questionnaire was first prepared in English and translated into Amharic, the national language. Pre-test was carried out on five percent of the total sample size before the actual data collection.

\section{Data Processing and Analysis}

Data were analyzed by using SPSS version 21.0. Binary logistic regression model conducted to assess predictors of diet and physical activity among study participants at a $\mathrm{P}$-value $<0.05,95 \%$ confidence interval and odds ratio.

\section{Ethical Consideration}

We have confirmed that our study is conducted in accordance with the declaration of Helsinki. We got ethical clearance and approval from the institutional review board of Mekelle University. Moreover, written informed consent was obtained. All the participants were voluntary to give written informed consent and obtained. Their privacy and confidentiality were kept in a ways we used coded and self-administered questionnaire. Moreover, we have informed the participants about the aim, method anticipated risks and benefit of the study. Furthermore, we have informed the study participants that they have full right not to fill the questionnaire.

\section{Results}

\section{Socio-Demographic Characteristics of Study Participants}

Among the total 633 study participants, more than 50\%, 389 (61.5\%) were males, of which $283(44.7 \%)$ had poor healthy diet practice and $195(30.8 \%)$ had poor physical activity practice. The Median age of the participants was $20.00(\mathrm{IQR}= \pm 3)$.

The result revealed that $131(20.7 \%)$ of the participants were in the monthly support category of $<300$ ETB with a median income of $300.00 \mathrm{ETB}$ ( $\mathrm{IQR}= \pm 500$ ), of those 113 $(17.9 \%)$ and $73(11.5 \%)$ had a poor healthy diet and physical activity practice, respectively.

This result showed that about half, $323(51.0 \%)$ of the students came from rural areas, $289(45.7 \%)$ and 165 (26\%) of them had poor healthy diet and physical activity practice respectively. Besides, the result indicated that the majority, 620 (97.9\%) of the students were currently living in their dorms.
Regarding father's and mother's occupation, more than half, $526(83.1 \%)$ of the respondent's fathers were employed. And $353(55.8 \%)$ of the student's mothers were unemployed (Table 1).

\section{Healthy Diet Practice}

According to this result, $208(32.86 \%)$ of the students were sometimes and $157(24.8 \%)$ were never made an effort to select foods without too much oil. The result also indicated that $352(55.6 \%)$ of the students were some times and $135(21.3 \%)$ never ate $2-4$ serving of fruit each day. Moreover, 484 (76.5\%) of the students were sometimes eating 3-5 servings of vegetables each day. Furthermore, among the total study participants, 252 (39.8\%) were never and $173(27.3 \%)$ were sometimes taken at least $1500 \mathrm{cc}$ of water daily (Table 2 ).

\section{Physical Activity Practice}

The result showed that among the total study participants, $398(62.9 \%)$ were never and $180(28.4 \%)$ were sometimes followed a planned exercise program. This result also revealed that $351(55.4 \%)$ of the students were sometimes and $155(24.9 \%)$ never exercised rigorously $30 \mathrm{~min}$ at least 3 times per week.

Moreover, the result indicated that 314 (49.6\%) of the students never and $144(22.7 \%)$ sometimes took part in leisure-time (recreational) physical activities (such as swimming, dancing, bicycling). Furthermore, the result revealed that only $45(7.1 \%)$ students were routinely and 65 (10.2\%) often participated in a physical fitness class at school weekly (Table 3).

\section{Overall Assessment of Healthy Diet Practice and Physical Activity}

The result indicated that $432(68.2 \%)$ and $378(59.7 \%)$ of the study participants had poor diet practice and physical activity respectively (Figure 1).

\section{Factors Associated with Healthy Diet Practice and Physical Activity}

Variables such as college and parent's resident were identified as predictors for healthy diet practice among college students.

Students from CNCS \& CBE were less by $31 \%$ and $20 \%$ to have healthy diet than students from CHS respectively (AOR: $0.69,95 \%$ CI: [0.034-0.137], AOR: 0.20, 95\% CI: [0.104.391]) (Table 4). 


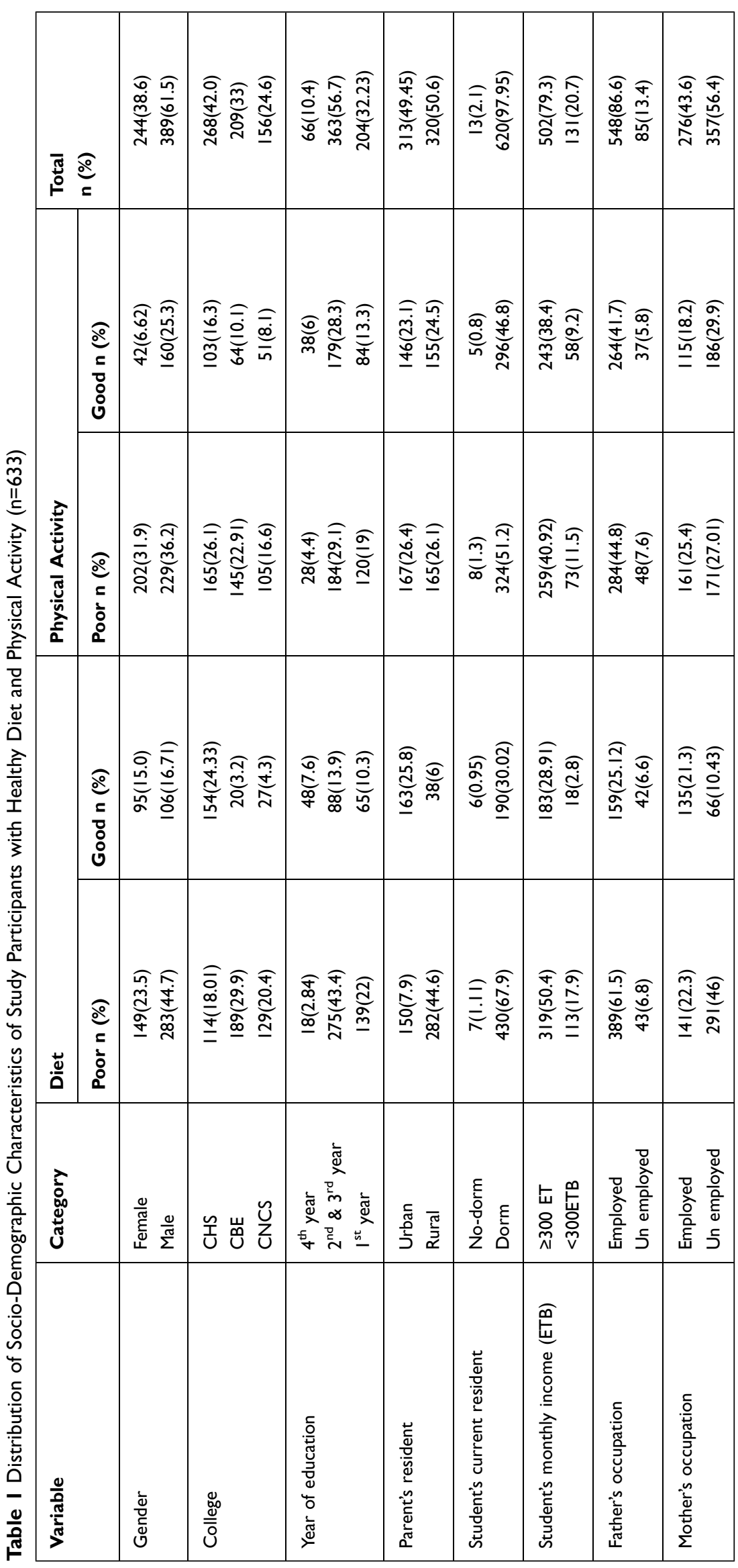


Table 2 Distribution of Healthy Diet Practice of Regular Under Graduate Students of Mekelle University, Tigray, Ethiopia, 2019 $(n=633)$

\begin{tabular}{|c|c|c|c|c|}
\hline Items & Never & Sometimes & Often & Routinely \\
\hline Follow a planned exercise program & $398(62.9 \%)$ & $180(28.4 \%)$ & $38(6 \%)$ & $17(2.7 \%)$ \\
\hline Perform stretching exercise daily & $156(24.6 \%)$ & $266(42 \%)$ & $180(28.4 \%)$ & $31(4.9 \%)$ \\
\hline Exercise vigorously $30 \mathrm{~min}$ at least 3 times per week & $35 \mathrm{I}(55.5 \%)$ & $155(24.5 \%)$ & $80(12.6 \%)$ & $47(7.4 \%)$ \\
\hline Participate in physical fitness class at school weekly & $385(60.8 \%)$ & $\mid 38(2 \mid .8 \%)$ & $65(10.3 \%)$ & $45(7.1 \%)$ \\
\hline $\begin{array}{l}\text { Take part in leisure-time (recreational) physical activities (such as swimming, dancing, } \\
\text { bicycling). }\end{array}$ & $314(49.6 \%)$ & $144(22.7) \%$ & $108(17.1 \%)$ & $67(10.6 \%)$ \\
\hline $\begin{array}{l}\text { Get exercise during usual daily activities (such as walking during lunch, using stairs } \\
\text { instead of elevators, parting car away from destination and walking) }\end{array}$ & $104(16.4 \%)$ & $139(22 \%)$ & $289(45.7 \%)$ & $101(16 \%)$ \\
\hline Warm up before rigorous exercise & $183(28.9 \%)$ & $29(4.6 \%)$ & $152(24 \%)$ & $52(8.2 \%)$ \\
\hline Make an effort to stand or sit straight & $147(\%)$ & $253(\%)$ & $178(\%)$ & $55(\%)$ \\
\hline
\end{tabular}

Table 3 Distribution of Physical Activity of Students of Mekelle University $(n=633)$

\begin{tabular}{|c|c|c|c|c|}
\hline Items & Never & Sometimes & Often & Routinely \\
\hline Follow a planned exercise program & $398(62.9 \%)$ & $180(28.4 \%)$ & $38(6 \%)$ & $17(2.7 \%)$ \\
\hline Perform stretching exercise daily & $156(24.6 \%)$ & $266(42 \%)$ & $180(28.4 \%)$ & $31(4.9 \%)$ \\
\hline Exercise vigorously $30 \mathrm{~min}$ at least 3 times per week & $35 I(55.5 \%)$ & $155(24.5 \%)$ & $80(12.6 \%)$ & $47(7.4 \%)$ \\
\hline Participate in physical fitness class at school weekly & $385(60.8 \%)$ & $138(2 \mid .8 \%)$ & $65(10.3 \%)$ & $45(7.1 \%)$ \\
\hline $\begin{array}{l}\text { Take part in leisure-time (recreational) physical activities (such as swimming, dancing, } \\
\text { bicycling). }\end{array}$ & $314(49.6 \%)$ & I44(22.7) \% & $108(17.1 \%)$ & $67(10.6 \%)$ \\
\hline $\begin{array}{l}\text { Get exercise during usual daily activities (such as walking during lunch, using stairs } \\
\text { instead of elevators, parting car away from destination and walking) }\end{array}$ & $104(16.4 \%)$ & $139(22 \%)$ & $289(45.7 \%)$ & $101(16 \%)$ \\
\hline Warm up before rigorous exercise & $183(28.9 \%)$ & $29(4.6 \%)$ & $152(24 \%)$ & $52(8.2 \%)$ \\
\hline Make an effort to stand or sit straight & $147(\%)$ & $253(\%)$ & $178(\%)$ & $55(\%)$ \\
\hline
\end{tabular}

The likelihood of having healthy diet was 1.331 times more likely higher among students who came from rural areas (AOR: 1.331, 95\% CI: [0.156-0.698]) compared to their counterparts.

Regarding physical activity gender, year of education and college, were significantly associated with physical activity.

The likelihood of being physically active was almost four times more likely higher among Male students (AOR: 3.909, 95\% CI: [2.549-5.993]) compared to females.

First-year students were less by $58.9 \%$ to have good physical activity than fourth-year students (AOR: 0.411, 95\% CI: [0.204-0.826]). Students from CNCS were less by $64.2 \%$ to have good physical activity than students from CHS (AOR: 0.358, 95\% CI: [0.212-0.604]) (Table 5).

\section{Discussion}

The current study revealed that the majority (68.2\%) of the students had poor diet. This result found that 135 (21.3\%) of the students never ate 2-4 servings of fruit each day and only $95(15 \%)$ of the students were often ate $3-5$ servings of vegetables each day. This result is similar to previous studies conducted in Saudi ${ }^{17}$ \& United Kingdom ${ }^{24}$ where, they reported a low intake of fruits and vegetables. In contrast, finding from Chinese students has indicated that students were taken higher amount of fruits and vegetables. This might be described by the fact that the prominent foods in Chinese traditional eating are fruits and vegetables. ${ }^{25}$ 


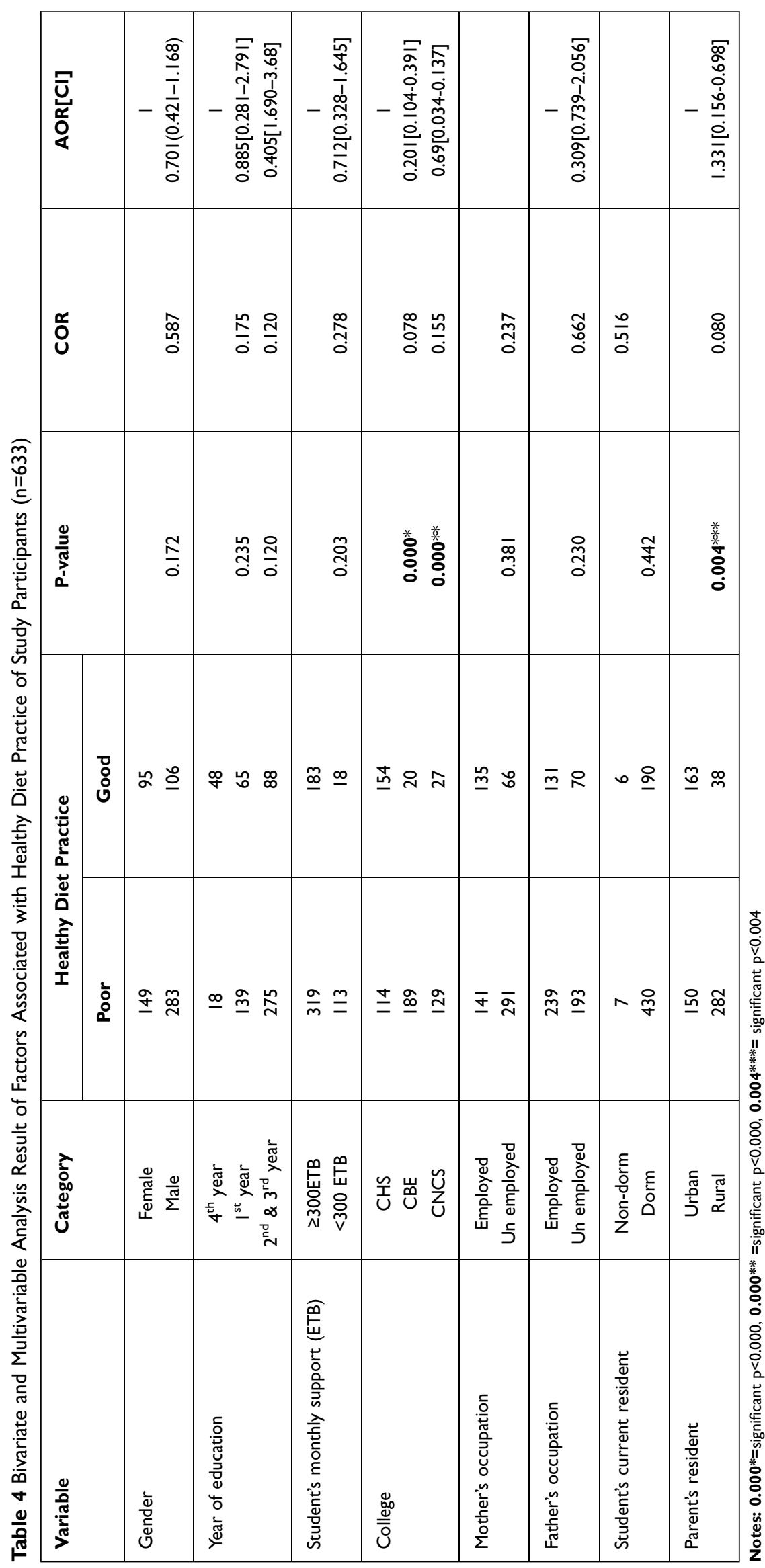




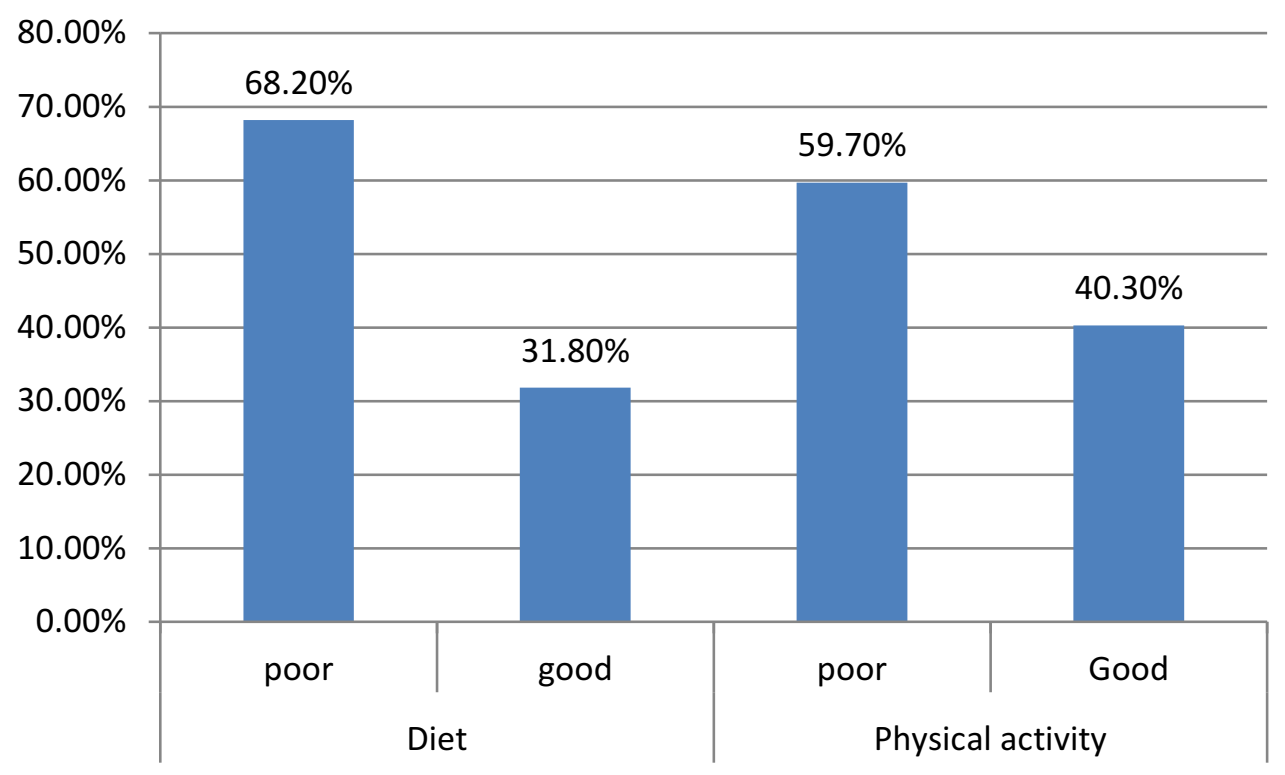

Figure I Status of healthy diet and physical activity practices of study participants $(n=633)$.

The present study indicated that only $21(3.3 \%)$ and 55 $(8.7 \%)$ of the students were routinely limit the use of sugars and foods containing sugars and include dietary fiber respectively. This indicated that students are not choosing diets low in fat. Our present study also revealed that majority of students was eating breakfast, which was similar with the finding similar study in Saudi students. ${ }^{17}$

The current study showed that college and parent's resident were significantly associated with the healthy diet. Moreover, students from CBE \& CNCs were less likely to have good healthy diet practice than students from CHS. This might be due to the fact that students from College of health science may have good health knowledge.

The present study revealed that students who came from urban areas were less likely to have good healthy diet practice compared with students who came from rural areas. This result is concurrent with the previous study conducted in China. ${ }^{26}$

Regarding physical activity, the overall practice was $431(68.3 \%)$ poor and $202(31.9 \%)$ good. The present study showed that majority of the students were never follow a planned exercise program. This result was congruent with the study conducted in Saudi. ${ }^{17}$ The current study also indicated that the majority of the university students never exercised vigorously $30 \mathrm{~min}$ at least 3 times per week. This result was similar to previous studies, which showed inadequate levels of intensive physical activity. ${ }^{27-29}$

The present study revealed that only 45 (7.1\%) of the students participated in physical fitness classes at school weekly. This finding was similar to previous research conducted in the University of Maribor, Slovenia, in southeastern Europe. ${ }^{30}$ The finding showed that few numbers of participants participated in a physical fitness classes and only $20.2 \%$ of the students reported adequate physical activity. The result also showed that the majority (289 (45.7\%) of the students got exercise during usual daily activities. This result was incongruent to previous studies in USA, ${ }^{31}$ Saudi $^{17}$ \& Malaysia. ${ }^{32}$ This difference might be due to the University environment factors and socio- economic factors.

In the present study, it has shown that gender, year of education and college were significantly associated with physical activity. The study indicated that male students were more likely to have good physical activity as compared with female students. The result was similar to previous findings from China ${ }^{16}$ Japan $^{33} \operatorname{Iran}^{34}$ \& Saudi. ${ }^{17}$ Furthermore, freshman students were less likely to have good physical activity as compared with fourthyear year students. This might be due to fact that freshman students encounter new experiences and responsibilities and, hence may not give special attention to exercise as much as fourth-year students do. In addition to that freshman students have less health knowledge than fourth-year students.

The current study revealed that students from CNCS \& CBE were less likely to have good physical activity as compared with students from CHS. This might be due to the fact that these students have good health knowledge. 


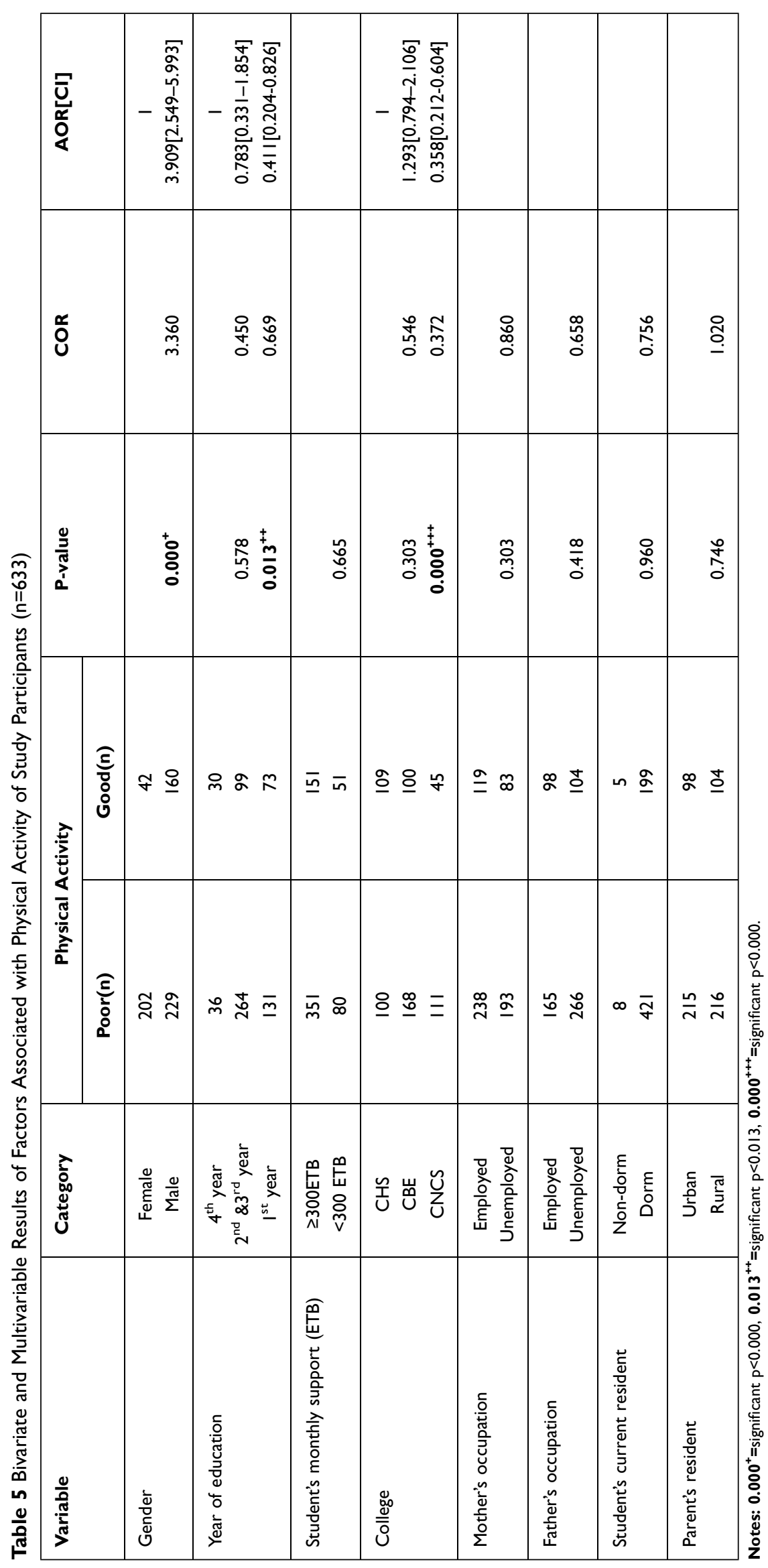




\section{Strength and Limitation of the Study}

Our study is the first study to assess healthy diet and physical activity among college students in our country Ethiopia. Moreover, the study findings can be generalized to the population because of the large sample size, sampling procedures, and high response rate of study participants. One limitation was since the tool is selfadministered questionnaire, the respondents might not pay full attention to it/read it properly.

\section{Conclusion}

The study found that the majority of the study participants were poor in both healthy diet and physical activity. Moreever, the present study showed that college and parent's resident were significantly associated with healthy diet practice. Whereas gender, year of education and college, were significantly associated with physical activity. Who are looking to demonstrate the efficacy of the changes in life style practice and the educational curricula, as well as to engage in collaborative research.

\section{Recommendation}

It is imperative to formulate curriculum and counseling services aimed at providing students with awareness, support and empowerment needed to make informed choices pertaining to their health. Moreover, future researches need to conduct this topic with the help of qualitative study.

\section{Acknowledgments}

We would like to express our deep gratitude to Mekelle University. We also acknowledge our data collectors and the study participants for their willingness.

\section{Author Contributions}

All authors made substantial contributions to conception and design, acquisition of data, or analysis and interpretation of data; took part in drafting the article or revising it critically for important intellectual content; agreed to submit to the current journal; gave final approval of the version to be published; and agree to be accountable for all aspects of the work.

\section{Disclosure}

The authors report no conflicts of interest in this work.

\section{References}

1. Carpenito- Ziglio E, Currie C, Rasmussen VB. The WHO crossnational study of health behavior in school aged children from 35 countries: findings from 2001-2002. J School Health. 2004;74 (6):204-206.

2. Peltzer K, Pengpid S, Samuels T, et al. Prevalence of overweight/ obesity and its associated factors among university students from 22 countries. Int J Environ Res Public Health. 2014;11(7):7425-7441. doi:10.3390/ijerph110707425

3. Misra A, Vikram NK. Insulin resistance syndrome (metabolic syndrome) and obesity in Asian Indians: evidence and implications. Nutrition. 2004;20(5):482-491. doi:10.1016/j.nut.2004.01.020

4. Organization WH. Global status report on noncommunicable diseases 2014. World Health Organization; 2014.

5. Yahia N, Wang D, Rapley M, Dey R. Assessment of weight status, dietary habits and beliefs, physical activity, and nutritional knowledge among university students. Perspect Public Health. 2016;136 (4):231-244.

6. Artinian NT, Fletcher GF, Mozaffarian D, et al. Interventions to promote physical activity and dietary lifestyle changes for cardiovascular risk factor reduction in adults: a scientific statement from the American Heart Association. Circulation. 2010;122(4):406-441. doi:10.1161/CIR.0b013e3181e8edf1

7. Lichtenstein AH, Appel LJ, Brands M, et al. Diet and lifestyle recommendations revision 2006: a scientific statement from the American Heart Association Nutrition Committee. Circulation. 2006;114(1):82-96. doi:10.1161/CIRCULATIONAHA.106.176158

8. Nelson KM, Reiber G, Boyko EJ. Diet and exercise among adults with type 2 diabetes: findings from the third national health and nutrition examination survey (NHANES III). Diabetes Care. 2002;25(10):1722-1728. doi:10.2337/diacare.25.10.1722

9. Terrio K, Auld GW. Osteoporosis knowledge, calcium intake, and weight-bearing physical activity in three age groups of women. $J$ Community Health. 2002;27(5):307-320. doi:10.1023/ A:1019840709367

10. Gutierrez J, Alloubani A, Mari M, Alzaatreh M. Cardiovascular disease risk factors: hypertension, diabetes mellitus and obesity among Tabuk Citizens in Saudi Arabia. Open Cardiovasc Med J. 2018;12:41. doi:10.2174/1874192401812010041

11. Ali N, Mahmood S, Manirujjaman M, et al. Hypertension prevalence and influence of basal metabolic rate on blood pressure among adult students in Bangladesh. BMC Public Health. 2018;18(1):58. doi:10.1186/s12889-017-4617-9

12. Gyamfi D, Obirikorang C, Acheampong E, et al. Prevalence of prehypertension and hypertension and its related risk factors among undergraduate students in a Tertiary institution, Ghana. Alexandria $j$ Med. 2018;54(4):475-480. doi:10.1016/j.ajme.2018.02.002

13. Damiri B, Aghbar A, Alkhdour S, Arafat Y. Characterization and prevalence of metabolic syndrome among overweight and obese young Palestinian students at An-Najah National University. Diabetes Metabol Syndr. 2018;12(3):343-348. doi:10.1016/j. dsx.2017.12.021

14. Hassan SM, Iftikhar O, Wali S, Ali S, Imran M. prevalence of prediabetes among students of ayub medical college, abbottabad. Pakj Health Sci. 2018;2(2):77-79.

15. Jawed S, Tariq S, Jamil Z, Ali R, Rehman R. Life style practices and health risk behaviors of medical students: a cross sectional study.

16. Mak YW, Kao AH, Tam LW, Virginia WC, Don TH, Leung DY. Health-promoting lifestyle and quality of life among Chinese nursing students. Prim Health Care Res Dev. 2018;19(6):629-636. doi:10.1017/S1463423618000208

17. Almutairi KM, Alonazi WB, Vinluan JM, et al. Health promoting lifestyle of university students in Saudi Arabia: a cross-sectional assessment. BMC Public Health. 2018;18(1):1093. doi:10.1186/ s12889-018-5999-z 
18. Al-Hazzaa HM, Abahussain NA, Al-Sobayel HI, Qahwaji DM, Musaiger AO. Physical activity, sedentary behaviors and dietary habits among Saudi adolescents relative to age, gender and region. Int J Behav Nutri Phys Activity. 2011;8(1):140. doi:10.1186/14795868-8-140

19. Yahia N, Wang D, Rapley M, Dey R. Assessment of weight status, dietary habits and beliefs, physical activity, and nutritional knowledge among university students. Perspect Public Health. 2016;136 (4):231-244

20. Lowry R, Galuska DA, Fulton JE, Wechsler H, Kann L. Weight management goals and practices among US high school students: associations with physical activity, diet, and smoking. $J$ Adolescent Health. 2002;31(2):133-144. doi:10.1016/S1054139X(01)00408-6

21. Baybutt M, Chemlal K. Health-promoting prisons: theory to practice. Glob Health Promot. 2016;23(1_suppl):66-74. doi:10.1177/ 1757975915614182

22. Newton J, Dooris M, Wills J. Healthy universities: an example of a whole-system health-promoting setting. Glob Health Promot. 2016;23(1_suppl):57-65. doi:10.1177/1757975915601037

23. Walker SN, Sechrist KR, Pender NJ. The health-promoting lifestyle profile: development and psychometric characteristics. Nurs Res. 1987;36(2):76-81. doi:10.1097/00006199-198703000-00 002

24. Sprake EF, Russell JM, Cecil JE, et al. Dietary patterns of university students in the UK: a cross-sectional study. Nutr J. 2018;17(1):90. doi:10.1186/s12937-018-0398-y

25. Sakamaki R, Toyama K, Amamoto R, Liu CJ, Shinfuku N. Nutritional knowledge, food habits and health attitude of Chinese university students-a cross sectional study-. Nutr J. 2005;4(1):4. doi:10.1186/1475-2891-4-4
26. Yang Y, Hu XM, Chen TJ, Bai MJ. Rural-urban differences of dietary patterns, overweight, and bone mineral status in Chinese students. Nutrients. 2016;8.

27. Leino-Arjas P, Solovieva S, Riihimäki H, Kirjonen J, Telama R. Leisure time physical activity and strenuousness of work as predictors of physical functioning: a 28 year follow up of a cohort of industrial employees. Occup Environ Med. 2004;61(12):1032-1038. doi:10.1136/oem.2003.012054

28. Mustard CA, Vermeulen M, Lavis JN. Is position in the occupational hierarchy a determinant of decline in perceived health status? Soc Sci Med. 2003;57(12):2291-2303. doi:10.1016/j.socscimed.2003.08.001

29. Hassmen P, Koivula N, Uutela A. Physical exercise and psychological well-being: a population study in Finland. Prev Med. 2000;30 (1):17-25. doi:10.1006/pmed.1999.0597

30. Lipošek S, Planinšec J, Leskošek B, Pajtler A. PHYSICAL activity of university students and its relation to physical fitness and academic success. Annales Kinesiologiae. 2019;9(2):89-104. doi:10.35469/ ak.2018.171

31. Huang TT, Harris KJ, Lee RE, Nazir N, Born W, Kaur H. Assessing overweight, obesity, diet, and physical activity in college students. $\mathrm{J} \mathrm{Am}$ Coll Health. 2003;52(2):83-86. doi:10.1080/07448480309595728

32. Goje M, Salmiah MS, Ahmad Azuhairi A, Jusoff K. Physical inactivity and its associated factors among university students. IOSR J Dental Med Sci. 2014;13(10):119-130. doi:10.9790/0853-13101119130

33. Wei CN, Harada K, Ueda K, Fukumoto K, Minamoto K, Ueda A. Assessment of health-promoting lifestyle profile in Japanese university students. Environ Health Prev Med. 2012;17(3):222. doi:10.1007/s12199-011-0244-8

34. Musavian AS, Pasha A, Rahebi SM, Roushan ZA, Ghanbari A. Health promoting behaviors among adolescents: a cross-sectional study. Nurs Midwifery Studies. 2014;3:1. doi:10.17795/nmsjournal14560
Nutrition and Dietary Supplements

\section{Publish your work in this journal}

Nutrition and Dietary. Supplements is an international, peerreviewed, open access journal focusing on research into nutritional requirements in health and disease, impact on metabolism and the identification and optimal use of dietary strategies and supplements necessary for normal growth and development. The journal welcomes submitted papers covering original research, basic science,

\section{Dovepress}

clinical \& epidemiological studies, reviews and evaluations, guidelines, expert opinion and commentary, case reports and extended reports. The manuscript management system is completely online and includes a very quick and fair peer-review system, which is all easy to use. Visit http://www.dovepress.com/testimonials.php to read real quotes from published authors. 